\title{
CHARLES BRUCKER, Fol et Folie en ancien français. Étude sémantique et stylistique
}

\author{
Maria Colombo Timelli
}

\section{OpenEdition}

\section{Journals}

\section{Édition électronique}

URL : http://journals.openedition.org/studifrancesi/14873

DOI : ERREUR PDO dans /localdata/www-bin/Core/Core/Db/Db.class.php L.34 : SQLSTATE[HYO00]

[2006] MySQL server has gone away

ISSN : 2421-5856

\section{Éditeur}

Rosenberg \& Sellier

\section{Édition imprimée}

Date de publication : 1 décembre 2018

Pagination : 473

ISSN : 0039-2944

\section{Référence électronique}

Maria Colombo Timelli, " CHARLES BRUCKER, Fol et Folie en ancien français. Étude sémantique et stylistique », Studi Francesi [En ligne], 186 (LXII | III) | 2018, mis en ligne le 01 janvier 2019, consulté le 07 janvier 2021. URL : http://journals.openedition.org/studifrancesi/14873; DOI : https://doi.org/ERREUR PDO dans /localdata/www-bin/Core/Core/Db/Db.class.php L.34 : SQLSTATE[HY000] [2006] MySQL server has gone away

Ce document a été généré automatiquement le 7 janvier 2021.

\section{(c) $($ ) $(9)$}

Studi Francesi è distribuita con Licenza Creative Commons Attribuzione - Non commerciale - Non opere derivate 4.0 Internazionale. 


\title{
CHARLES BRUCKER, Fol et Folie en ancien français. Étude sémantique et stylistique
}

\author{
Maria Colombo Timelli
}

\section{RÉFÉRENCE}

CHARLES BRUCKER, Fol et Folie en ancien français. Étude sémantique et stylistique, Bruxelles,

P.I.E. Peter Lang, 2017, 247 pp.

1 Trente ans séparent ce beau livre de Charles Brucker de son ouvrage sur Sage et sagesse au Moyen Âge (Genève, 1987): la méthode en est la même, prenant en compte les aspects sémantiques des termes objet d'étude ainsi que le contexte littéraire et par conséquent les aspects stylistiques et sémiotiques des différents emplois. Fol et folie imposent par ailleurs l'évaluation de deux registres, intellectuel et moral, en couvrant des nuances de sens qu'il n'est pas toujours aisé de reconnaître et par rapport auxquelles Ch.B. montre une sensibilité très aigüe.

2 Son ouvrage est organisé en trois parties, dont les deux premières - intitulées tout simplement Fol, pp.23-112, et Folie, pp.113-185-suivent la même structure, en présentant les données et l'analyse selon l'ordre chronologique et en tenant compte de la succession générique: la première moitié $\mathrm{du} \mathrm{XII}^{\mathrm{e}}$ siècle comprend chansons de geste, littérature morale et religieuse, genre historique; les années 1150-1180 voient la naissance et apogée de la littérature courtoise, sans que soient négligés, là encore, les textes moraux et les chansons de geste, auxquels s'ajoute la littérature dite «bourgeoise». Au cours de cette première période, c'est surtout la richesse sémantique de fol qui frappe, comprenant des sémèmes très variés: 'stupide', 'imprudent', 'qui a perdu le bon sens / la raison', 'déraisonnable', 'perfide'. Une évolution se dessine dans la seconde moitié du XII siècle, avec l'ajout de nouvelles nuances: fol peut alors correspondre à 'léger (moralement)', 'lâche', 'coupable', mais aussi 'extraordinaire', et 
encore 'ignorant', 'naïf, 'malhonnête', 'méprisable', 'frivole' 'démesuré'... Quant à la distribution de l'adjectif dans les textes qui constituent le corpus de Ch.B., on ne sera pas surpris de relever l'intérêt du Tristan de Béroul (où fol peut signifier 'coupable', 'qui a commis le péché d'adultère'), ou de repérer le sémème relativement rare de 'fou de cour' dans le Conte du Graal de Chrétien. Pour ce qui est du substantif, folie couvre évidemment des significations proches, mais semble se spécialiser dans certains contextes, notamment religieux.

3 La troisième partie, consacrée à l'évolution ultérieure des deux termes, se justifie dans la mesure où le XIII siècle semble marquer une césure, en particulier dans le nombre d'occurrences, qui baisse sensiblement, et parallèlement dans un sémantisme qui se stabilise tout en se réduisant par rapport à la richesse constatée pour la période précédente. On soulignera l'intérêt du dernier chapitre de cette section, qui compare d'abord fréquence et sémantisme de fol vs sage et de folie dans l'ensemble de la littérature médiévale, pour mettre ensuite l'adjectif en réseau avec quelques synonymes (sot, nice, desvé, forsené, bricon, estout / estoutie, nonsage, nonsavant).

4 La Bibliographie sépare nécessairement le corpus (pp.223-228) et les études (pp. 228-236); elle s'accompagne d'un Index chronologique des auteurs et des ceuvres (pp. 237-240) et d'un Index des auteurs, des ceuvres, des notions et des sémèmes (pp. 241-247) qui simplifie sensiblement la consultation du volume et le repérage des informations fondamentales. 